\title{
A Non-Conventional Interaction on Computational Systems Based on Mouth Puffing
}

\author{
Erick M. Campos \\ Universidade Federal do Pará \\ Belém, Brasil \\ erickcampos@ufpa.br
}

\author{
Cassio T. Batista \\ Universidade Federal do Pará \\ Belém, Brasil \\ cassiotb@ufpa.br
}

\author{
Alexandre A. Freitas \\ Universidade Federal do Pará \\ Belém, Brasil \\ afreitas@ufpa.br
}

\author{
Bianchi S. Meiguins \\ Universidade Federal do Pará \\ Belém, Brasil \\ bianchi@ufpa.br
}

\author{
Renan F. Cunha \\ Universidade Federal do Pará \\ Belém, Brasil \\ renan@ufpa.br
}

\author{
Nelson C. Sampaio Neto \\ Universidade Federal do Pará \\ Belém, Brasil \\ nelsonneto@ufpa.br
}

\begin{abstract}
Computer mice and keyboards have for long been the dominant input devices for desktop computers. Nonetheless, they still represent quite a barrier - especially for people whose upper-limb motor skills are compromised. This work proposes a low-cost, mouth-puffing-based device that is able to perform the mouse click on computational platforms. Additionally, a driver was developed to allow the device to communicate with the computer via audio jack P2 interface. The mouse cursor is controlled by head tracking thanks to eViacam software. The evaluation took place by comparing the proposed equipment with the dwell time method on navigation tasks elaborated over websites.
\end{abstract}

\section{ACM Classification Keywords}

H.5.2. Information Interfaces and Presentation (e.g HCI): User Interfaces; B.0. Hardware: General; D.0. Software: General; K.4.2. Computers and Society: Social Issues

\section{Author Keywords}

Puff switch; non-conventional interaction; alternative mouse; assistive technology.

\section{INTRODUCTION}

This work presents a mouth-puffing based switch that was configured to act as the mouse left button for clicking, which was then compared to the dwell time method for evaluation. The dwell time is one of the most commonly used alternative methods of clicking and uses a predetermined time in which the pointer is over a region to perform the click event. The mouth-puffing as a method of interaction was chosen because it is an action that can be performed by people with different

Permission to make digital or hard copies of all or part of this work for personal or classroom use is granted without fee provided that copies are not made or distributed for profit or commercial advantage and that copies bear this notice and the full citation on the first page. Copyrights for components of this work owned by others than ACM must be honored. Abstracting with credit is permitted. To copy otherwise or republish, to post on servers or to redistribute to lists, requires prior specific permission and/or a fee. Copyright 2018 SBC.

IHC 2018, Anais Estendidos do XVII Simpósio Brasileiro sobre Fatores Humanos em Sistemas Computacionais

Outubro 22-26, 2018, Belém, Brasil

PÔSTERES VIRTUAIS E DEMOS disability profiles. A piezoelectric disc has been used as a pressure sensor on a hardware circuit that is placed close to the user's mouth. The project was designed to be low cost, so a software driver was also built to allow the device to communicate with the computer via audio jack P2 interface through an aux cable, which is in fact cheaper than USB. Additionally, in order to integrate the puff-based sensor into a complete mouse-like system, the head-tracking feature provided by the eViacam software [2] was used, allowing the user to movement the mouse cursor with head movements.

Finding academic research that use mouth-puffing AT switches as an alternative method of clicking is very difficult. Only FlipMouse [1] was found in the searches performed. However, as well as the other works on AT switches, details about the development of this tool are not presented, which turns the possibility to build one's own prototype a difficult task.

\section{THE PROPOSED PUFF-BASED SWITCH}

The puff-based device was built with the intention of being open-source and low-cost, so that more people can eventually afford a tool that can be used as an alternative method for mouse clicking. The prototype developed in this work is shown in Figure 1.

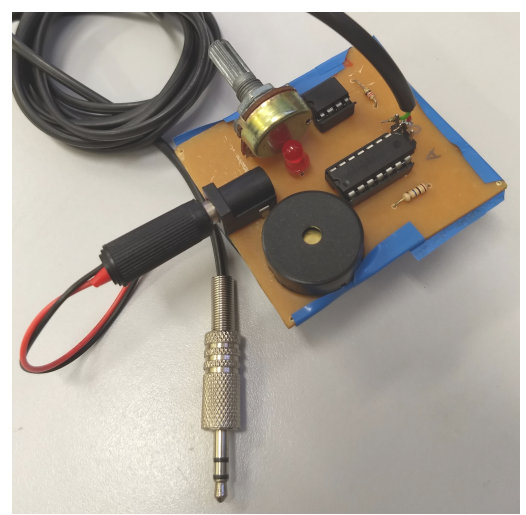

Figure 1. Puff-based switch. 
The puff action is perceived by a piezo disc coupled over the device, which converts mechanical energy into electricity through the piezoelectric effect [4]. A TRS audio connector was used to communicate the device with computational systems. PortAudio [5] and Xlib [3] libraries were used to capture the signals from the piezo disc under UNIX operating systems and translate them to mouse clicks, respectively.

\section{RESULTS AND DISCUSSION}

The study was conducted with seven males and three females, a total of 10 participants with ages varying from 21 to 28 years old. All of them are either undergraduate or graduate students from the Federal University of Pará. Each participant performed a pre-established routine of clicks on YouTube (https: //www . youtube. com/) and G1 (https://g1.globo.com/) websites, first using the mouth-puffing method proposed in this work and then using the dwell time method. The puff-based switch was compared to the dwell time method with respect to i) the total number of click errors committerd on both websites; ii) the time taken to complete the tasks.

Figure 2 shows the amount of click errors committed by participants in both websites. On YouTube, the number of errors was very similar in both click methods. Most mouth-puffing method errors occurred due to unsuccessful clicks when participants were not puffing at the correct intensity for a click to occur. With dwell time, there were more unintentional clicks due to errors in eViacam at tracking the user's face.

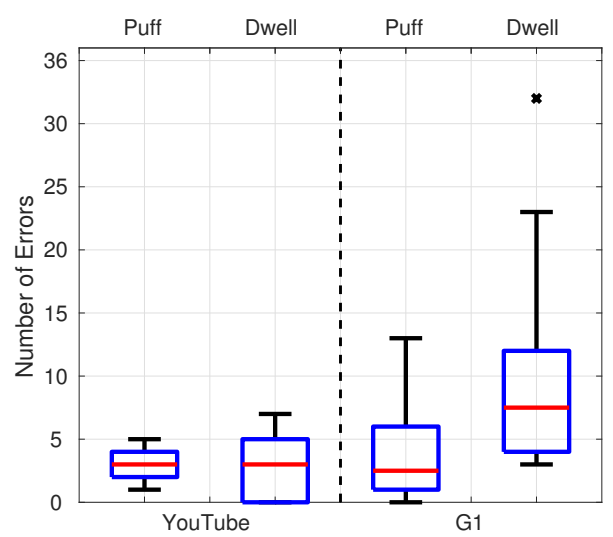

Figure 2. Distribution of the number of click errors.

In the G1 task, the dwell time was the method that presented most errors. This happened because the menu items on this website are very close to each other, and this forced the user to move the cursor more slowly, which often was an enough time for the click to occur.

Figure 3 shows the execution time of each task. In the task of Youtube, dwell time was better than the puff-based method. This happened because the YouTube task was executed first using the puff-based method. When the participants performed the same task with the dwell time, they were more used to the routines to be performed.

On the other hand, in the G1 task, the puff-based method was better than the dwell time, since the participants made many click errors using dwell time. This happened because

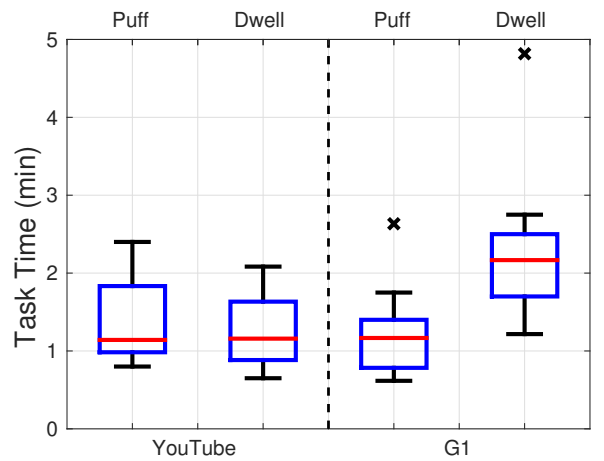

Figure 3. Distribution of the completion time of the tasks.

the task of the G1 was more problematic to be executed due to the proximity of the items of the menu of the website that ended up influencing the considerable increase at the time of execution.

It is important to mention that the participants were asked to give suggestions about the puff-based tool and they suggested the possibility of three levels of device sensitivity in order to improve the efficiency of the proposed device.

\section{CONCLUSIONS}

The method proposed in this work proved to be quite efficient to be used as an alternative method of click. In websites that do not have clickable items too close to each other, the dwell time method was slightly better, as seen at the execution times and number of click errors smaller than the puff-based method. However, in the case of websites that do have items close to each other, such as G1, the puff-based method proved to be a better solution than dwell time.

The proposed device can also be used as a general purpose AT switch since it has as output the audio interface P2 Jack. In addition, with the software that captures audio signals and converts them to click events, it is even possible to connect any switch that has the P2 Jack interface to be used as an alternative method of click too.

\section{REFERENCES}

1. Benjamin Aigner, Veronika David, Martin Deinhofer, and Christoph Veigl. 2016. FLipMouse: A Flexible Alternative Input Solution for People with Severe Motor Restrictions. In Proceedings of the 7th International Conference on Software Development and Technologies for Enhancing Accessibility and Fighting Info-exclusion (DSAI 2016). ACM, New York, NY, USA, 25-32. DOI : http://dx.doi.org/10.1145/3019943.3019948

2. Cmauri. 2018. GitHub - eViacam: Webcam Based Mouse Emulator. (2018). https://github.com/cmauri/eviacam

3. X.Org Foundation. 2018. iXlib - C Language X Interface. (2018). ftp://www.x.org/

4. B. Jaffe. 2012. Piezoelectric Ceramics. Elsevier Science. https://books.google.com.br/books?id=GJC_MBEM4VMC

5. PortAudio. 2018. An Open-Source Cross-Platform Audio API. (2018). http://portaudio.com/ 